\title{
Studies on structural, mechanical and erosive wear properties of ZA-27 alloy-based micro-nanocomposites
}

\begin{tabular}{|c|c|}
\hline Journal: & Proc. IMechE Part L: Journal of Materials: Design and Applications \\
\hline Manuscript ID & JMDA-20-0525 \\
\hline Manuscript Type: & Original article \\
\hline Date Received/Accepted: & 18 December 2020 / 26 January 2021 \\
\hline Complete List of Authors: & $\begin{array}{l}\text { Vencl, Aleksandar; Mechanical Engineering Faculty, University of } \\
\text { Belgrade, Tribology Laboratory } \\
\text { Kandeva, Mara; Faculty of Industrial Technology, Technical University of } \\
\text { Sofia } \\
\text { Zadorozhnaya, Elena; South Ural State University, Motor transport } \\
\text { Svoboda, Petr; Faculty of Mechanical Engineering, Brno University of } \\
\text { Technology } \\
\text { Michalec, Michal; Faculty of Mechanical Engineering, Brno University of } \\
\text { Technology } \\
\text { Milivojević, Aleksandar; University of Belgrade - Faculty of Mechanical } \\
\text { Engineering, Engineering Materials and Welding, Tribology, Fuels and } \\
\text { Combustion } \\
\text { Trdan, Uros; Faculty of Mechanical Engineering, University of Ljubljana }\end{array}$ \\
\hline Keywords: & $\begin{array}{l}\text { ZA-27 alloy, micro-nanocomposites, compocasting, microstructure, } \\
\text { hardness, erosive wear }\end{array}$ \\
\hline Abstract: & $\begin{array}{l}\text { Metal matrix nanocomposites represent relatively new class of material, } \\
\text { which are still extensively investigated. However, most of the studies are } \\
\text { devoted to aluminium- or magnesium-based nanocomposites and only a } \\
\text { few to zinc alloy base nanocomposites, and even fewer to zinc alloy base } \\
\text { micro-nanocomposites. In addition, most of the tribological studies } \\
\text { investigate adhesive or abrasive wear resistance, whereas studies of } \\
\text { erosive wear resistance lag well behind. It was previously shown that the } \\
\text { presence of nanoparticles in ZA-27 alloy-based nanocomposites led to } \\
\text { slightly increase of erosive wear resistance, so the aim was to produce } \\
\text { micro-nanocomposites that will retain the positive effect of nanoparticles } \\
\text { and obtain improvements due to the addition of microparticles together } \\
\text { with nanoparticles. The ZA-27 alloy-based micro-nanocomposites were } \\
\text { reinforced with } 3 \text { wt. \% Al2O3 microparticles (particle size approx. } 36 \\
\mu m \text { ) and with four different amounts ( } 0.3,0.5 \text {, } 0.7 \text { and } 1 \text { wt. \%) of } \\
\text { Al2O3 nanoparticles (particle size } 20-30 \text { nm). Tested materials were } \\
\text { produced by the compocasting process, with mechanical alloying pre- } \\
\text { processing. Solid particle erosive wear testing, with particle impact angle } \\
\text { of } 90^{\circ} \text {, showed that all micro-nanocomposites had significantly increased } \\
\text { wear resistance in comparison to the reference material. }\end{array}$ \\
\hline
\end{tabular}

This is a pre-print of an article published in Proceedings of the Institution of Mechanical Engineers, Part L: Journal of Materials: Design and Applications. The final authenticated version is available online at: https://doi.org/10.1177/1464420721994870 


\begin{abstract}
Metal matrix nanocomposites represent relatively new class of material, which are still extensively investigated. However, most of the studies are devoted to aluminium- or magnesium-based nanocomposites and only a few to zinc alloy base nanocomposites, and even fewer to zinc alloy base micro-nanocomposites. In addition, most of the tribological studies investigate adhesive or abrasive wear resistance, whereas studies of erosive wear resistance lag well behind. It was previously shown that the presence of nanoparticles in ZA-27 alloy-based nanocomposites led to slightly increase of erosive wear resistance, so the aim was to produce micro-nanocomposites that will retain the positive effect of nanoparticles and obtain improvements due to the addition of microparticles together with nanoparticles. The ZA-27 alloy-based micro-nanocomposites were reinforced with 3 wt. \% $\mathrm{Al}_{2} \mathrm{O}_{3}$ microparticles (particle size approx. $36 \mu \mathrm{m}$ ) and with four different amounts $\left(0.3,0.5,0.7\right.$ and $1 \mathrm{wt}$. \%) of $\mathrm{Al}_{2} \mathrm{O}_{3}$ nanoparticles (particle size 20-30 nm). Tested materials were produced by the compocasting process, with mechanical alloying preprocessing. Solid particle erosive wear testing, with particle impact angle of $90^{\circ}$, showed that all micronanocomposites had significantly increased wear resistance in comparison to the reference material.
\end{abstract}

Keywords: ZA-27 alloy, micro-nanocomposites, compocasting, microstructure, hardness, erosive wear

\title{
1. Introduction
}

In recent years, extensive research efforts have been made to develop nanocomposite materials by using different ingot metallurgy (casting) processes. Most of these studies were related to development of nanocomposites with aluminium ${ }^{1-3}$ or magnesium ${ }^{4,5}$ alloy base and with the addition of ceramic nanoreinforcements. On the other hand, there are much less studies focused on nanocomposites with zinc alloys base, ${ }^{6-9}$ despite the fact that there are numerous research activities related to development of such microcomposites. ${ }^{10-12}$ The most frequently used zinc alloy base is ZA-27, a zinc-aluminium alloy with relatively high aluminium content, ${ }^{13}$ whereas for the production of microcomposites different secondary phases were used, e.g. $\mathrm{SiC}, \mathrm{Al}_{2} \mathrm{O}_{3}$ and other ceramic particles, ${ }^{10-12}$ graphite particles ${ }^{14}$ and short glass fibres. ${ }^{15}$

The ZA-27 alloy is a commercial casting alloy, which can be found in a wide range of applications, particularly in automotive industry due to the high strength to weight ratio. ${ }^{16}$ Due to its relatively high adhesive wear resistance, it has been frequently used in sliding bearings and bushings. ${ }^{17}$ Wide solidification interval, between liquidus and solidus temperature, allows processing of ZA-27 alloy in the semi-solid state $^{18}$ i.e. production of the composites with ZA-27 alloy base by the compocasting process. ${ }^{19}$ Compocasting process enables production of relatively cheap and quality metal matrix composites (MMCs) with a non-dendritic matrix structure. This process is carried out at substantially lower temperatures compared to the e.g. high-pressure die casting, thereby enabling energy savings, lower emissions and extended tool life. In addition, it is possible to obtain near net shape castings that can be later processed by stir casting, squeeze casting ${ }^{20}$ or by extrusion. ${ }^{21}$ 
Nowadays, compocasting process is also used for the production of metal matrix nanocomposites (MMnCs). Unlike MMCs in which the increased strength is accompanied by a decreased ductility (compared to the matrix alloy), the addition of nanoparticles in MMnCs lead to the beneficial increase of both strength and ductility, compared to the metal matrix. In order to further improve the properties of MMCs and/or MMnCs, research activities have also been focused on the production of composite materials that contain both micro- and nanoparticles. ${ }^{22,23}$ However, despite considerable progress in this area, little attention has been paid to the production and characterization of zinc alloys-based micro-nanocomposites. Hence, the aim of this paper was to investigate the production possibility of various ZA-27 alloy-based micronanocomposites through the compocasting process, as well as to analyse structural, mechanical and erosive wear properties of the obtained composites.

\section{Experimental details}

\subsection{Materials}

Matrix material was zinc-aluminium alloy ZA-27, with the chemical composition according to the ASTM standard. ${ }^{13}$ Type, size and amount of reinforcement particles used for obtaining of the microcomposite and micro-nanocomposites are shown in Table 1 . The investigated microcomposite (composite with the addition of $\mathrm{Al}_{2} \mathrm{O}_{3}$ microparticles only) was produced by the compocasting process on the apparatus, which is described elsewhere. ${ }^{24}$ Micro-nanocomposites (composites with the addition of $\mathrm{Al}_{2} \mathrm{O}_{3}$ microparticles and $\mathrm{Al}_{2} \mathrm{O}_{3}$ nanoparticles) were produced using the same process and apparatus, whereas the mechanical alloying of ceramic nanoparticles with ZA-27 alloy metal chips was applied beforehand. It was applied in order to reduce the formation of the $\mathrm{Al}_{2} \mathrm{O}_{3}$ nanoparticle cluster agglomerations in the matrix. Before this pre-processing, the ZA-27 alloy metal chips were thoroughly washed in trichloroethylene and then in ethanol for degreasing, while the $\mathrm{Al}_{2} \mathrm{O}_{3}$ nanoparticles were washed in ethanol before and heated to $400{ }^{\circ} \mathrm{C}$ in order to remove the moisture and contaminations. The mechanical alloying parameters were similar as in our previous study. ${ }^{25}$ The only difference is in metal chips-to-nanoparticles weight ratio (2:1 vs. 3:1). After mechanical alloying, the mixture of $\mathrm{ZA}-27$ alloy metal chips and $\mathrm{Al}_{2} \mathrm{O}_{3}$ nanoparticles was mixed with $\mathrm{Al}_{2} \mathrm{O}_{3}$ microparticles. The resulting mixture was homogenized for 60 minutes in a mixer without alumina balls.

Table 1. Designation of the produced composites and specification of used reinforcements

\begin{tabular}{|c|c|c|}
\hline \multirow[b]{2}{*}{$\begin{array}{l}\text { Composite } \\
\text { designation }\end{array}$} & \multicolumn{2}{|c|}{ Reinforcement amount, wt. \% } \\
\hline & $\begin{array}{c}\mathrm{Al}_{2} \mathrm{O}_{3} \text { microparticles } \\
\text { (approx. } 36 \mu \mathrm{m} \text { ) }\end{array}$ & $\begin{array}{c}\mathrm{Al}_{2} \mathrm{O}_{3} \text { nanoparticles } \\
(20-30 \mathrm{~nm})\end{array}$ \\
\hline Micro & \multirow[t]{5}{*}{$\begin{array}{lll} \\
\end{array}$} & - \\
\hline $\mathrm{MN}-0.3$ & & 0.3 \\
\hline $\mathrm{MN}-0.5$ & & 0.5 \\
\hline $\mathrm{MN}-0.7$ & & 0.7 \\
\hline $\mathrm{MN}-1.0$ & & 1.0 \\
\hline
\end{tabular}

Compocasting process started with the matrix alloy overheating at $550{ }^{\circ} \mathrm{C}$, and cleaning of the slag. Afterwards, the temperature of the melt was reduced to $500{ }^{\circ} \mathrm{C}$, followed by mixing of the melt with a stirrer at $250 \mathrm{rpm}$. Infiltration of the mixture, obtained in mechanical alloying process, started at this temperature and lasted for 3 minutes. After the infiltration, mixing of the melt at increased rate of $500 \mathrm{rpm}$ lasted for 5 minutes. Then, with continued mixing, the temperature of the melt was reduced further to $465{ }^{\circ} \mathrm{C}$ (cooling rate of $5{ }^{\circ} \mathrm{C} / \mathrm{min}$ ). Additional mixing at this temperature was continued for 8 minutes, after which the melt was poured into preheated mould (at $480^{\circ} \mathrm{C}$ ) made of steel. Reference material was ZA-27 alloy, produced by thixocasting (designated as ZA-TX). The parameters of thixocasting and compocasting process were similar, for the purpose of comparison. The matrix alloy was first overheated at $550{ }^{\circ} \mathrm{C}$, and the slag was cleaned. After that, the temperature of the melt was reduced to $500{ }^{\circ} \mathrm{C}$, followed by mixing of the melt with a stirrer at $500 \mathrm{rpm}$, for 5 minutes. Then, with continued mixing, the temperature of the melt is reduced further to $465^{\circ} \mathrm{C}$ (cooling rate of $5^{\circ} \mathrm{C} / \mathrm{min}$ ). Additional mixing at this temperature was continued 


\section{Results and discussion}

The microstructure of the thixocasted ZA-27 alloy is non-dendritic, and regions of $\alpha$ phase (dark gray areas), $\alpha+\eta$ phase mixture (middle gray areas) and $\eta$ phase (light gray areas) can be noticed (Fig. 1). The regions of $\alpha$ phase and $\alpha+\eta$ phase mixture form elliptical microconstituents. Transformation of dendritic to non-dendritic structure occurred under the influence of shear forces during mixing of the ZA-27 alloy semisolid melt. According to the Al-Zn phase diagram, ${ }^{16}$ solidification of conventional cast ZA-27 alloy begins with the formation of $\alpha$ phase nuclei. The growth of the nuclei in the melt during solidification results in formation of $\alpha$ phase particles. At peritectic temperature, the $\alpha$ phase particles (dendrites) react with the melt, and high temperature $\beta$ phase is formed at edges of the $\alpha$ phase particles. The $\beta$ phase is unstable at lower temperatures. ${ }^{29}$ During further cooling, the $\beta$ phase transforms into the $\alpha+\eta$ phase mixture so that the $\alpha$ phase and the $\alpha+\eta$ phase mixture form a dendritic shape microconstituents. 

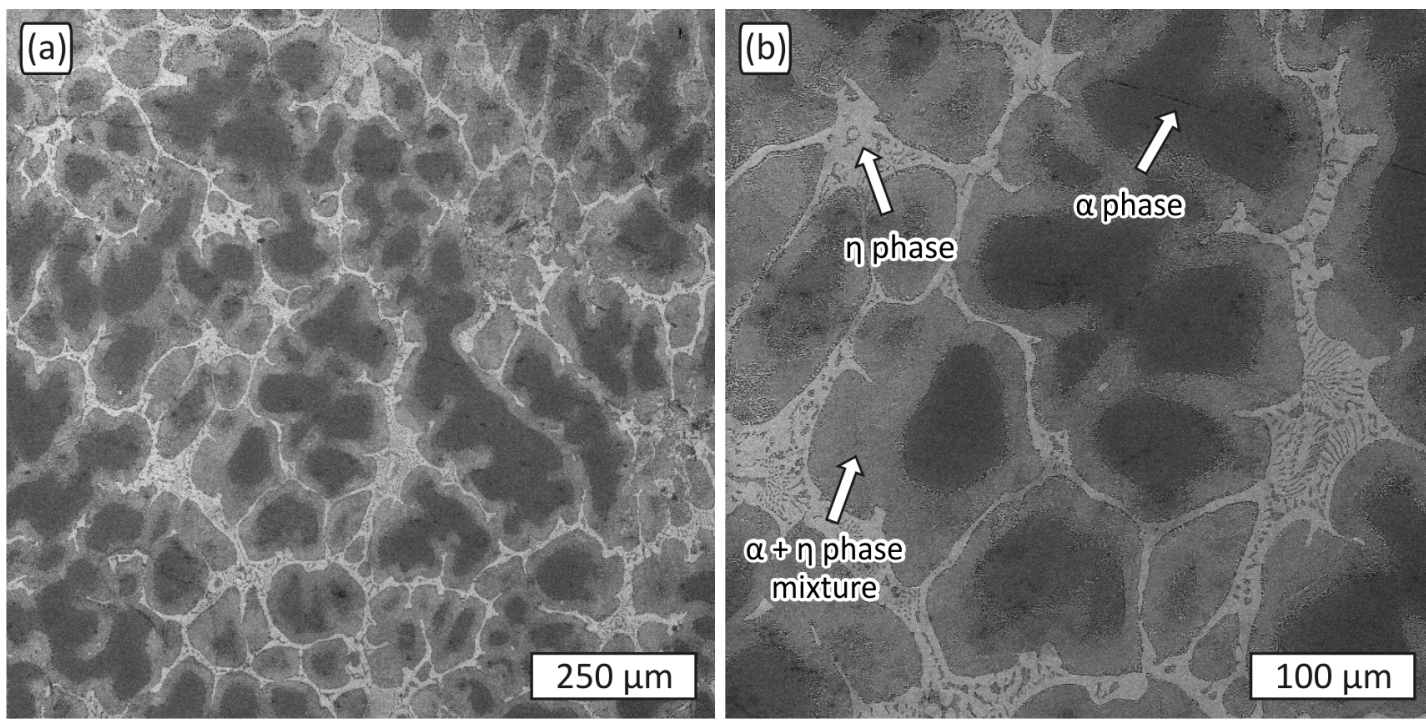

Figure 1. Microstructure of thixocasted ZA-27 alloy, SEM: (a) general view and (b) $\alpha$ phase formed by deagglomeration of large $\alpha$ phase region

In the conventionally casted structure, when the process of solidification takes place without the influence of external forces, the $\alpha$ phase formats the dendrite cores, while the $\alpha+\eta$ phase mixture is present in the proximity of dendrites. The $\eta$ phase is the interdendritic phase. Due to the influence of the shear forces during mixing (thixocasting process), the $\alpha$ phase (dendrites) are transformed into a nondendritic shape (deformed ellipses). During thixocasting process, the cooling time of the semi-solid melt in the preheated mould was longer, which resulted in a prolonged peritectic reaction and expanded regions of $\alpha+\eta$ phase mixtures (Fig. 1). Agglomeration and deagglomeration of primary particles of the solid phase occur under the influence of shear forces during mixing of semi-solid melts. ${ }^{30}$ Large regions of $\alpha$ phase that are formed by agglomeration of smaller elliptic $\alpha$ phase regions can be seen in Figure 1a, while regions of $\alpha$ phase formed by deagglomeration of large $\alpha$ phase region are clearly visible in Figure $1 \mathrm{~b}$.

Microstructures of all micro-nanocomposites were very similar (Figs. 2 and 3). General view of the microstructure (Fig. 2a) confirms that the $\mathrm{Al}_{2} \mathrm{O}_{3}$ microparticles are placed in the regions of $\alpha+\eta$ phase mixture, and that the structure of micro-nanocomposites matrix is the same as the structure of thixocasted ZA-27 alloy. The distribution of $\mathrm{Al}_{2} \mathrm{O}_{3}$ microparticles (particle size approx. $36 \mu \mathrm{m}$ ) is analysed on higher magnification image (Fig. 2b). A good mechanical bonding between the incorporated $\mathrm{Al}_{2} \mathrm{O}_{3}$ microparticles and the metal matrix, with low content of porosity and without contact between the particles was obtained. This is very significant for achieving good mechanical properties, as well as high erosive wear resistance. Groups of $\mathrm{Al}_{2} \mathrm{O}_{3}$ nanoparticle clusters (denoted with white arrows) can also be noticed on Figure $2 \mathrm{~b}$.
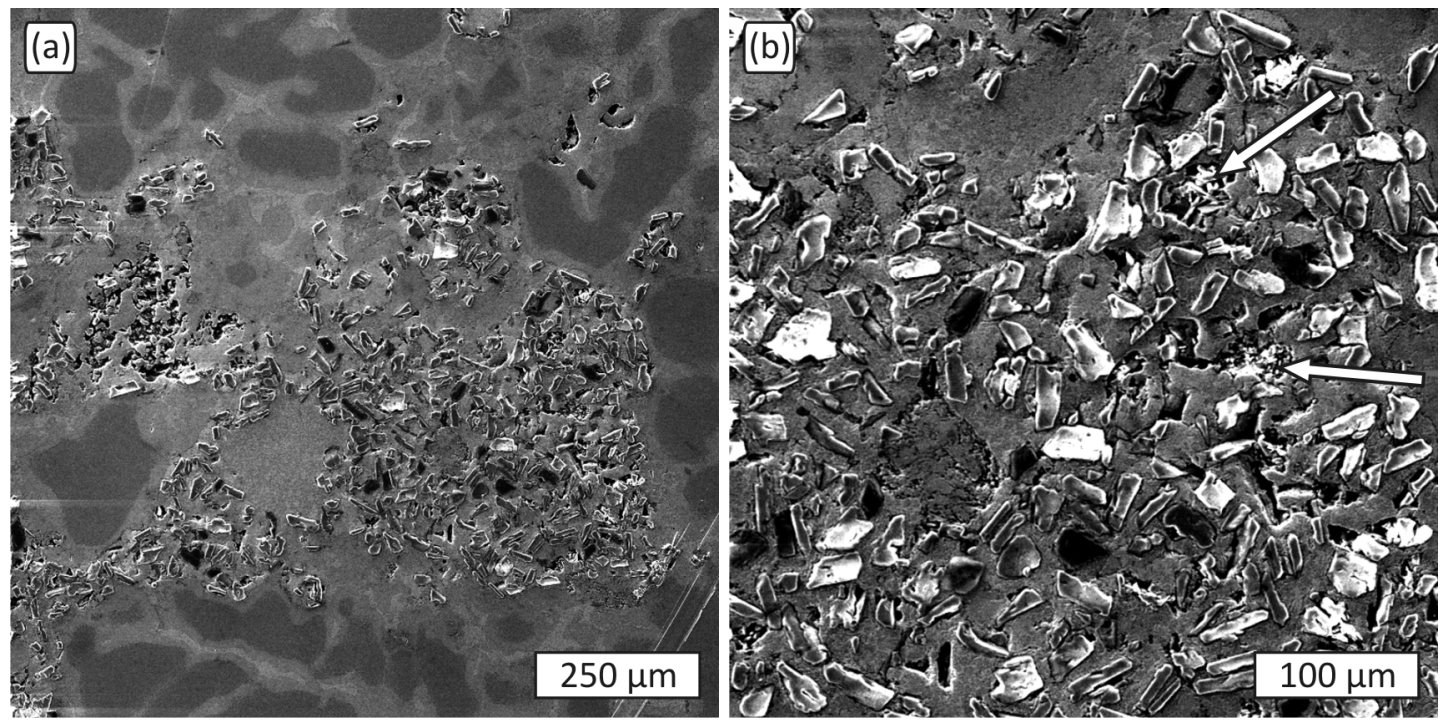

Figure 2. Microstructure of micro-nanocomposite MN-0.3, SEM: (a) general view, (b) microparticles distribution 

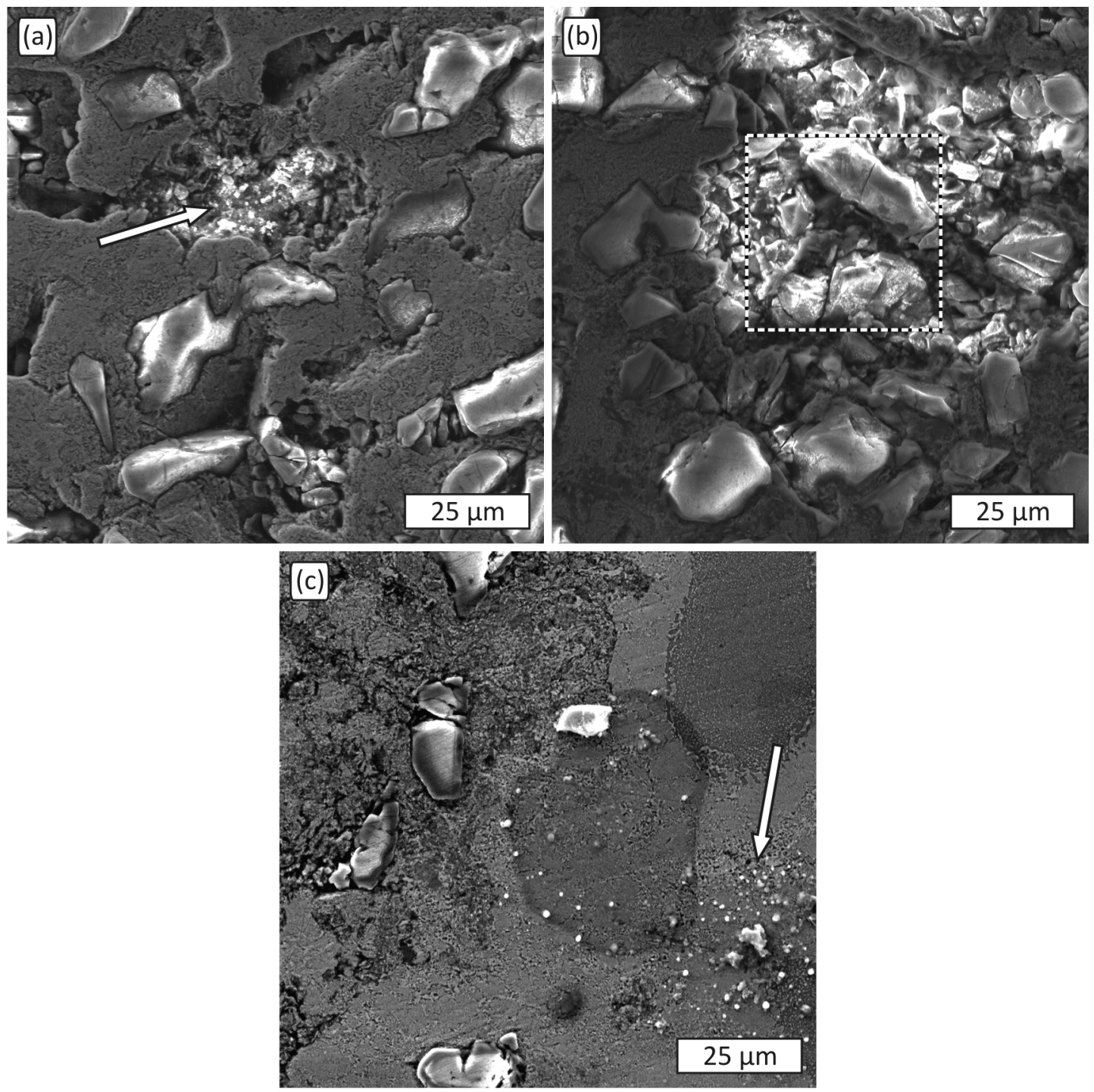

Figure 3. Microstructure of micro-nanocomposites (nanoparticle clusters distribution), SEM: (a) micro-nanocomposite $\mathrm{MN}-0.3$, (b) micro-nanocomposite MN-0.5 and (c) micro-nanocomposite MN-1.0

Example of $\mathrm{Al}_{2} \mathrm{O}_{3}$ nanoparticles agglomeration, composed of several small and large clusters, is clearly visible on Figure $3 \mathrm{a}$ (denoted with white arrow). These agglomerations and $\mathrm{Al}_{2} \mathrm{O}_{3}$ nanoparticle clusters are mainly randomly distributed within the microstructure. Sometime, they are placed between ceramic microparticles (Fig. 3b), which may prevent appropriate bonding between the microparticles and the matrix. In some cases, the presence of cracks in ceramic microparticles is also evident (denoted with rectangle on Fig. 3b). These microcracks probably appeared due to thermal stresses, which occurred during the cooling of the composite mixture. Their presence adversely affects the mechanical and erosive wear properties of the produced micro-nanocomposites. On the other hand, uniform distribution of the $\mathrm{Al}_{2} \mathrm{O}_{3}$ nanoparticle clusters and their favourable shape and size, should have a positive effect. Such example can clearly be observed in Figure $3 \mathrm{c}$ (denoted with white arrow), where $\mathrm{Al}_{2} \mathrm{O}_{3}$ nanoparticles clusters are circular, with size up to $2 \mu \mathrm{m}$, and uniformly distributed within the $\alpha+\eta$ phase mixture. 


\subsection{Hardness}

The macro- and microhardness results presented in Figures 4 and 5 confirm good repeatability of the results, where calculated standard deviations were below $8 \%$. The presented hardness values are lower than that obtained in our previous studies. ${ }^{26,27}$ Also, the prescribed values of hardness for sand/die cast ZA27 alloy are 113/119 HB..$^{13}$ Relatively lower hardness was probably obtained due to increase in the preheating temperature of the steel mould (from 400 to $480{ }^{\circ} \mathrm{C}$ ), and associated longer cooling time, i.e. smaller cooling rate of the samples. In addition, a change in the composting process in the mixing part could lead to loss of magnesium, which also could have diminishing effect on the hardness. As expected and as showed in some previous studies, ${ }^{31,32}$ microhardness values, which were measured with lower load, were slightly higher than macrohardness values.

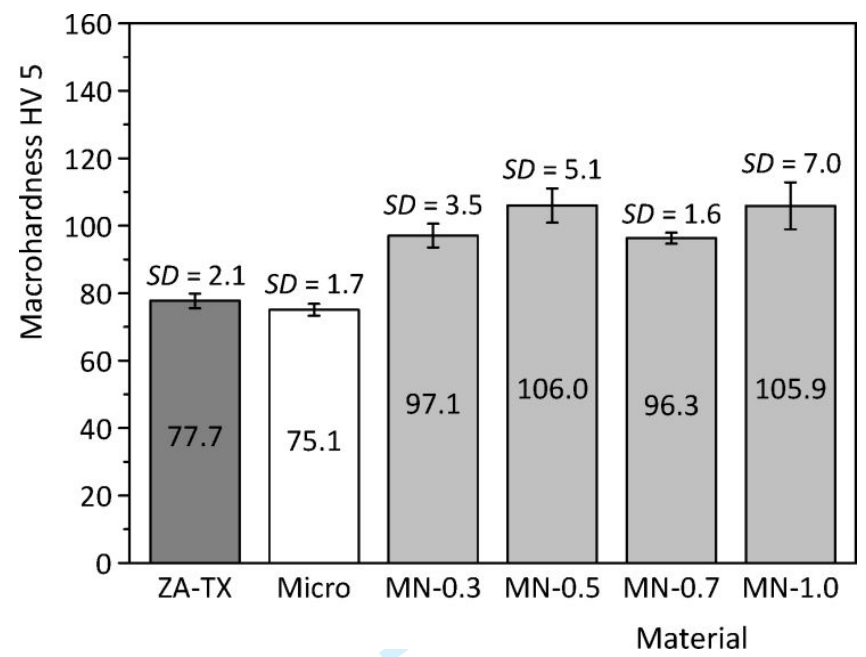

Figure 4. Macrohardness values and corresponding standard deviations $(S D)$ of tested materials

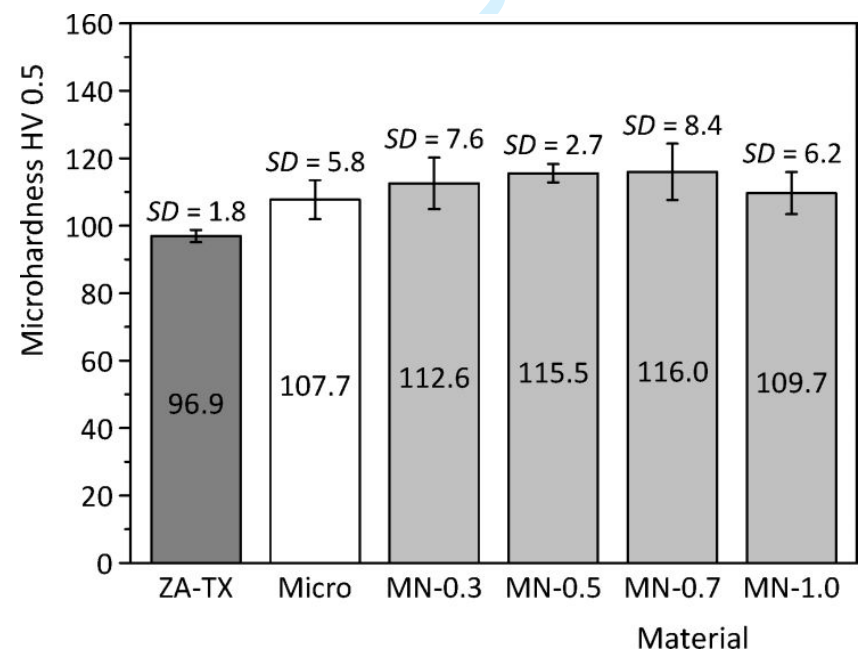

Figure 5. Microhardness values and corresponding standard deviations $(S D)$ of tested materials

All micro-nanocomposites achieved more-or-less similar hardness values, which were rather expected due to their similar microstructures. Although higher amount of nanoparticles should result in higher hardness of the nanocomposites, ${ }^{11}$ it should be noted that the hardness of composites also strongly depends on the interface between reinforcements and matrix as well as on distribution of the reinforcements. ${ }^{33}$ Positive effect of higher amount of nanoparticles on hardness diminishes with higher content of porosity. Microstructural examinations have confirmed favourable distribution of micro- and nanoparticles in the micro-nanocomposite with the lowest amount of the nanoparticles. The agglomerations of nanoparticles clusters are placed in the regions between the microparticles and contact between the nanoparticles and microparticles was not detected (Fig. 3a). Hence, lower porosity was 
achieved. On the other hand, with higher amount of nanoparticles more and more agglomerations of nanoparticle clusters are in contact with microparticles (Fig. 3b). Contact between the nanoparticles and microparticles led to the discontinuity of the microparticle/matrix interface, which adversely affected the load transfer from the matrix to the reinforcements and thereby decreased the hardness. In addition, microcracks within the microparticles were also noticed. Regardless of the nanoparticle amount, all micronanocomposites achieved higher hardness than thixocasted ZA-27 alloy. The average percentage increase of macrohardness was around $30 \%$, which is much higher than in the case when only nanoparticles were incorporated in the matrix alloy (around $9 \%$ ). ${ }^{26,27}$ This is probably due to the combination of different reinforcement mechanisms, i.e. difference in coefficients of thermal expansion (microparticles) and Orowan dislocation strengthening mechanism (nanoparticles).

\subsection{Erosive wear properties}

The wear rate results of the tested materials obtained by erosive wear testing are shown in Figure 6 . The standard deviation values of the erosive wear rates indicate that the repeatability of the results was acceptable, i.e. around $10 \%$. The wear rate of thixocasted ZA-27 alloy (ZA-TX) is very similar to the one obtained in our previous study, ${ }^{25}$ although the hardness of the same material in that study was higher. This can be explained by the fact that the hardness is directly related to erosive wear rate only for annealed pure metals in case when small impact angles are applied. ${ }^{34}$ Indeed, erosion is a complex phenomenon. For ductile metals it is impossible to use a single mechanical property or a simple combination of a few mechanical properties to predict its erosive wear resistance. ${ }^{35}$

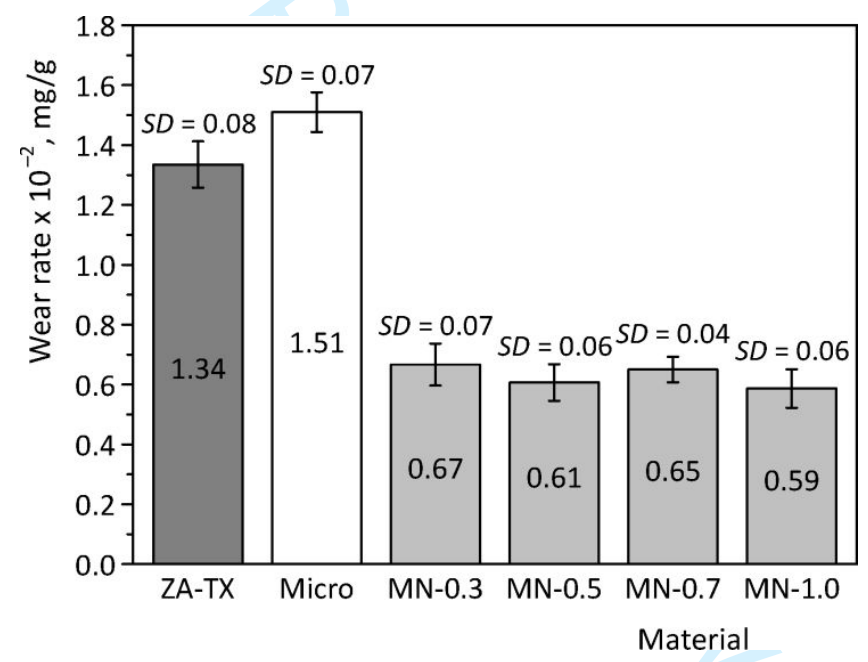

Figure 6. Erosive wear rate values and corresponding standard deviations $(S D)$ of tested materials

Results in Figure 6 clearly depict that the highest wear rate was obtained with the microcomposite material (composite with the addition of $3 \mathrm{wt} . \% \mathrm{Al}_{2} \mathrm{O}_{3}$ microparticles only). Despite the fact that this composite had similar hardness as the thixocasted ZA-27 alloy, its wear rate was slightly higher and could even increase with higher amount of $\mathrm{Al}_{2} \mathrm{O}_{3}$ microparticles. Especially since a harder MMCs can show higher erosion wear than a softer material. ${ }^{36}$ Although MMCs mostly experience higher abrasive and adhesive wear resistance than the matrix material, 37,38 their erosive wear behaviour is less predictable. Moreover, it has been shown that the erosive wear resistance of the aluminium alloy-based composites, carbide-metal composites, cermets, nickel-chromium superalloy composites and steel-based composites is often lower than that of the matrix material. ${ }^{35,39-41}$ Reduced erosive wear resistance of the MMCs reinforced with higher amount of micro-size ceramic particles is usually connected with significant lowering of the ductility. Hence, lower ductility results in reduced plastic deformation ability, which enhances the possibility of microfracture upon impact of the erosive particles. ${ }^{42}$

All micro-nanocomposites (composites with the addition of $\mathrm{Al}_{2} \mathrm{O}_{3}$ microparticles and $\mathrm{Al}_{2} \mathrm{O}_{3}$ nanoparticles) showed lower wear rate than the thixocasted ZA-27 alloy. The average reduction of wear rate compared to the reference material was in this case relatively high, i.e. $53 \%$. This suggests that the simultaneous addition of micro- and nanoparticles had a major, beneficial effect on erosive wear rate. This is most likely 
associated with the collateral effect of dual, i.e. micro- and nanoparticles reinforcement of the matrix material. Addition of micro- or nanoparticles separately does not show a strong influence on erosive wear rate reduction. For example, the addition of $\mathrm{Al}_{2} \mathrm{O}_{3}$ nanoparticles reduces wear rate only by approximately $6 \%$, ${ }^{25}$ while the addition of $\mathrm{Al}_{2} \mathrm{O}_{3}$ microparticles even increases the erosive wear rate (Fig. 6). In our previous study, ${ }^{26}$ it was shown that the addition of $\mathrm{Al}_{2} \mathrm{O}_{3}$ nanoparticles somehow increases hardness and compressive yield strength through the enhanced dislocation density strengthening mechanism. Most probably the addition of nanoparticles also increases the ductility of micro-nanocomposites, which is very important in erosive wear test with particles impact angle of $90^{\circ}$. This property combined with increased strength (due to the presence of ceramic microparticles) resulted in lower wear rate of micronanocomposites. Results of this study confirm similar wear rates of all micro-nanocomposites, which is in accordance with obtained microstructures and hardness. Theory suggests that the wear rate should be lower in micro-nanocomposites with higher amount of nanoparticles, but it is not the case mainly due to the structural imperfections that were noticed in all micro-nanocomposites (Figs. 2 and 3). Poor distribution of nanoparticles (agglomerations of clusters) and positioning around microparticles, as well as presence of cracked microparticles had a detrimental effect on erosive wear rate/resistance.

The SEM analyses of worn surfaces depicted in Figure 7, which were performed after testing, show typical erosive wear appearance of all worn surfaces. ${ }^{43}$ This generally includes several erosive wear mechanisms that usually occur simultaneously, i.e. microcutting and microploughing; surface cracking; extrusion of material at the exit of impact crater; surface or subsurface fatigue cracks due to the repeated impact; formation of thin platelets due to the extrusion and forging by repeated impact; and formation of platelets by a backward extrusion process. ${ }^{34}$ Plastic deformation of the surface with the occurrence of extruded material around the large indents and its smearing by subsequent impacts of particles, presence of scratches and grooves caused by ploughing action of particles which additionally caused progressive degradation of the surface with small and large wear debris can be observed on all samples. However, greater presence of surface cracks and presence of embedded erosive particles were not noticed. Relatively large size of the erosive particles $(\leq 630 \mu \mathrm{m})$ and other test parameters prevented embedment of the erosive particles. 

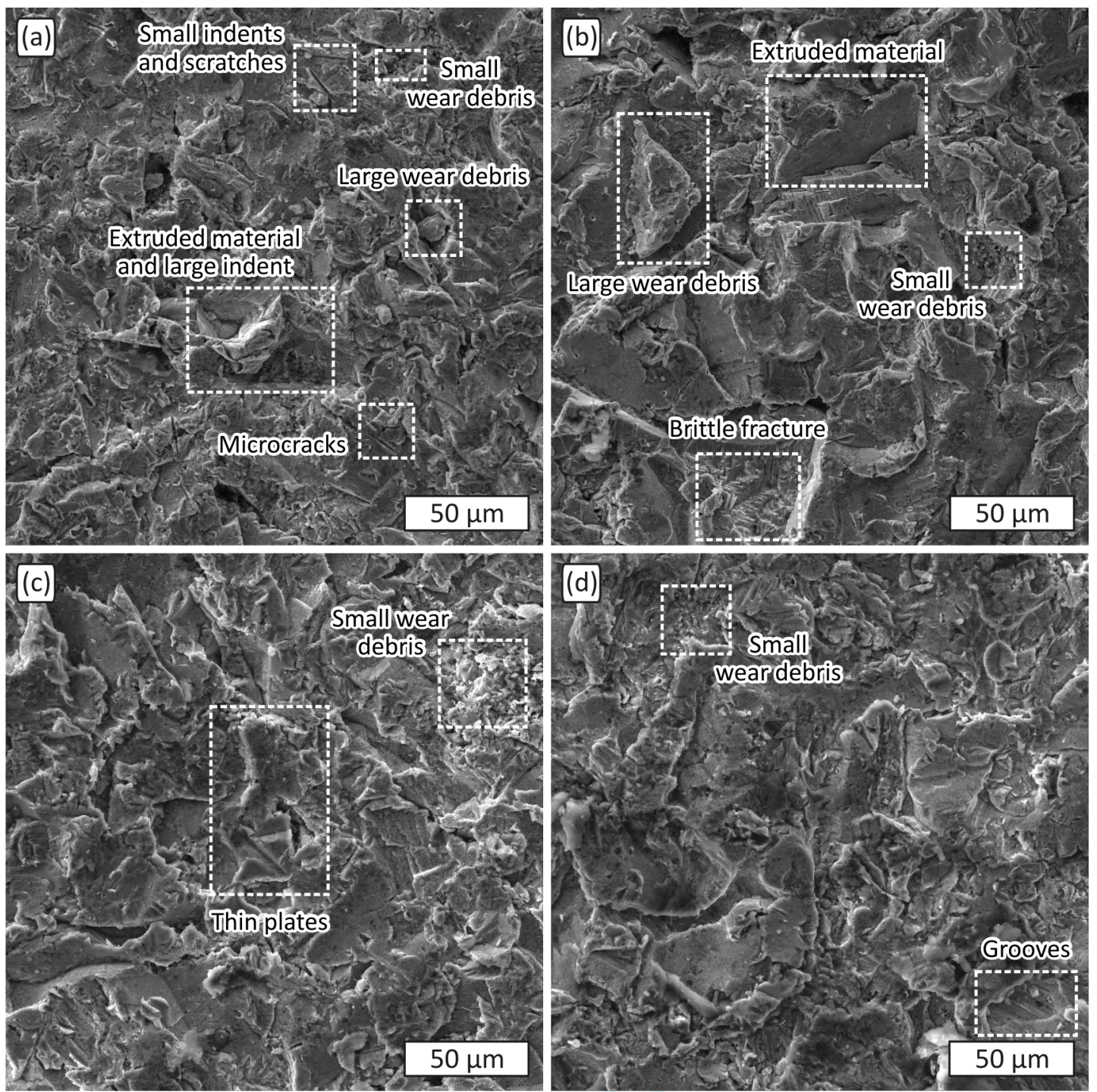

Figure 7. Worn surfaces of tested materials, SEM: (a) thixocasted ZA-27 alloy, (b) microcomposite, (c) micronanocomposite $\mathrm{MN}-0.3$ and (d) micro-nanocomposite $\mathrm{MN}-1$; all images are taken with the same magnification $(1000 \times)$

Differences in the appearance of the worn surface between tested materials are, first of all, in the severity of plastic deformation. This was more intensive at thixocasted ZA-27 alloy and microcomposite. In addition, the presence of relatively large wear debris and surface microcracks are also observed on the worn surface of thixocasted ZA-27 alloy (Fig. 7a). Formation of plastically deformed and extruded material is noticed around the large indents (craters). There are also some small indents and scratches, which most likely occurred during the impact of small and sharp erosive particles or its fragments (microcutting). Compared to the thixocasted ZA-27 alloy, indents on the worn surface of microcomposite are bigger and more massive (Fig. 7b). In addition, presence of large wear debris in the form of plates and even brittle fracture is noticed only on the worn surface of microcomposite.

Worn surfaces of all micro-nanocomposites were very similar (Figs. 7c and d). It agrees with the wear rates of these composites (Fig. 6), which all achieved similar values. Further, no large wear debris could be observed on their worn surfaces, in contrast to thixocasted ZA-27 alloy and microcomposite. On the other hand, presence of thin plates and grooves caused by ploughing action of erosive particles and ductile fracture (microploughing) were noticed only at worn surfaces of micro-nanocomposites. Formation of thin plates could be identified as one of the previously mentioned erosive wear mechanism, ${ }^{34}$ i.e. as "formation of thin platelets due to the extrusion and forging by repeated impact". In addition, since the particles impact angle was $90^{\circ}$, it is very presumable that plastic deformation and work hardening of the thin surface layer, with induced compressive residual stresses, occurred. ${ }^{42}$ All this provides a possible explanation for significantly higher erosive wear resistance of all micro-nanocomposites, compared to the thixocasted ZA27 alloy and microcomposite. 


\section{Conclusions}

In order to reduce the undesired formation of nanoparticle clusters in the matrix alloy, mechanical alloying of ceramic nanoparticles with a scrap of the matrix alloy was applied before the compocasting process. In such way, complex microparticles, more suitable for infiltration in the semi-solid matrix alloy during the compocasting process, were formed.

Microstructures of all micro-nanocomposites were very similar, i.e. there was no obvious relationship between the amount of $\mathrm{Al}_{2} \mathrm{O}_{3}$ nanoparticles and the microstructure of the produced micro-nanocomposites. The $\mathrm{Al}_{2} \mathrm{O}_{3}$ nanoparticles appeared in the form of relatively uniformly distributed clusters. In most cases, these clusters were not in direct contact with $\mathrm{Al}_{2} \mathrm{O}_{3}$ microparticles, which would prevent the appropriate bonding between the microparticles and the matrix. This is an important feature to obtain good mechanical properties and higher erosive wear resistance. All micro-nanocomposites achieved more-or-less similar hardness values. Regardless the amount of nanoparticles, hardness of micro-nanocomposites was higher than that of thixocasted ZA-27 alloy. The average percentage increase of macrohardness was around $30 \%$.

All micro-nanocomposites achieved similar erosive wear resistance, which was much higher than that of thixocasted ZA-27 alloy. The average reduction of wear rate was $53 \%$. Higher erosive wear rates were obtained due to the dual effect of simultaneously added micro- and nanoparticles. Most probably microparticles mainly increased strength and nanoparticles prevent lowering or even increase the ductility of the matrix material. In addition, SEM analyses showed that micro-nanocomposites had a specific worn surface appearance, suggesting that forging by repeated impact and work hardening of the surface most likely occurred.

\section{Acknowledgement}

This work has been performed as a part of activities within the project 451-03-68/2020-14/200105, supported by the Republic of Serbia, Ministry of Education, Science and Technological Development, and its financial help is gratefully acknowledged. Mara Kandeva acknowledges the project ДH 07/28-15.12.2016, funded by the National Science Fund of the Ministry of Education and Science, Bulgaria. Petr Svoboda and Michal Michalec acknowledge the project FSI-S-17-4415, funded by the Ministry of Education, Youth and Sports of Czech Republic. Uroš Trdan acknowledges the financial support from the state budget by the Slovenian Research Agency Programme No. P2-0270. Collaboration through the CEEPUS network CIII-BG0703, COST action CA15102 and bilateral Project 337-00-00111/2020-09/50 and BI-RS/20-21-047 between Republic of Serbia and Republic of Slovenia is also acknowledged.

$5-4$

\section{References}

1. Sajjadi SA, Torabi Parizi M, Ezatpour HR, et al. Fabrication of A356 composite reinforced with micro and nano $\mathrm{Al}_{2} \mathrm{O}_{3}$ particles by a developed compocasting method and study of its properties. J Alloys Compd 2012; 511: 226231.

2. Karbalaei Akbari M, Baharvandi HR and Mirzaee O. Nano-sized aluminum oxide reinforced commercial casting A356 alloy matrix: Evaluation of hardness, wear resistance and compressive strength focusing on particle distribution in aluminum matrix. Compos Part B: Eng 2013; 52: 262-268.

3. Karbalaei Akbari M, Baharvandi HR and Mirzaee O. Fabrication of nano-sized $\mathrm{Al}_{2} \mathrm{O}_{3}$ reinforced casting aluminum composite focusing on preparation process of reinforcement powders and evaluation of its properties. Compos Part B: Eng 2013; 55: 426-432.

4. Hassan SF and Gupta M. Development of high performance magnesium nanocomposites using solidification processing route. Mater Sci Technol 2004; 20: 1383-1388.

5. Lan J, Yang Y and Li X. Microstructure and microhardness of SiC nanoparticles reinforced magnesium composites fabricated by ultrasonic method. Mater Sci Eng A 2004; 386: 284-290.

6. Swiderska-Sroda A, Kalisz G, Grzanka E, et al. SiC-Zn nanocomposites obtained using the high-pressure infiltration technique. Solid State Phenom 2006; 114: 257-262. 
7. Karimzadeh $\mathrm{F}$, Enayati $\mathrm{MH}$ and Tavoosi $\mathrm{M}$. Synthesis and characterization of $\mathrm{Zn} / \mathrm{Al}_{2} \mathrm{O}_{3}$ nanocomposite by mechanical alloying. Mater Sci Eng A 2008; 486: 45-48.

8. De Cicco MP, Li X and Turng L-S. Semi-solid casting (SSC) of zinc alloy nanocomposites. J Mater Process Technol 2009; 209: 5881-5885.

9. Li ZG. Fabrication of in situ $\mathrm{TiB}_{2}$ particulates reinforced zinc alloy matrix composite. Mater Lett 2014; 121: 1-4.

10. Sharma SC, Girish BM, Somashekar DR, et al. Sliding wear behaviour of zircon particles reinforced ZA-27 alloy composite materials. Wear 1999; 224: 89-94.

11. Sastry S, Krishna M and Uchil J. A study on damping behaviour of aluminite particulate reinforced ZA-27 alloy metal matrix composites. J Alloys Compd 2001; 314: 268-274.

12. Sharma SC, Sastry S and Krishna M. Effect of aging parameters on the micro structure and properties of ZA27/aluminite metal matrix composites. J Alloys Compd 2002; 346: 292-301.

13. ASTM B 86:2013. Standard specification for zinc and zinc-aluminum (ZA) alloy foundry and die castings.

14. Seah KHW, Sharma SC and Girish BM. Mechanical properties of cast ZA-27/graphite particulate composites. Mater Des 1995; 16: 271-275.

15. Sharma SC, Girish BM, Satish BM, et al. Aging characteristics of short glass fiber reinforced ZA-27 alloy composite materials. J Mater Eng Perform 1998; 7: 747-750.

16. Gervais E, Barnhurst RJ and Loong CA. An analysis of selected properties of ZA alloys. JOM 1985; 37: 43-47.

17. Rac A, Babić M and Ninković R. Theory and practice of Zn-Al sliding bearings. J Balk Tribol Assoc 2001; 7: 234-240.

18. Chen TJ, Hao Y and Li YD. Effects of processing parameters on microstructure of thixoformed ZA27 alloy. Mater Des 2007; 28: 1279-1287.

19. Karni N, Barkay GB and Bamberger M. Structure and properties of metal-matrix composite. J Mater Sci Lett 1994; 13: 541-544.

20. Ribes $\mathrm{H}$ and Suéry M. Effect of particle oxidation on age hardening of Al-Si-Mg/SiC composites. Scr Metall 1989; 23: 705-709.

21. Rahmani Fard R and Akhlaghi F. Effect of extrusion temperature on the microstructure and porosity of $A 356-\mathrm{SiC}_{\mathrm{p}}$ composites. J Mater Process Technol 2007; 187-188: 433-436.

22. Rajmohan $\mathrm{T}$, Palanikumar $\mathrm{K}$ and Arumugam $\mathrm{S}$. Synthesis and characterization of sintered hybrid aluminium matrix composites reinforced with nanocopper oxide particles and microsilicon carbide particles. Compos Part $B$ : Eng 2014; 59: 43-49.

23. Karbalaei Akbari M, Baharvandi HR and Shirvanimoghaddam K. Tensile and fracture behavior of nano/micro $\mathrm{TiB}_{2}$ particle reinforced casting A356 aluminum alloy composites. Mater Des 2015; 66A: 150-161.

24. Vencl A, Bobić I, Jovanović MT, et al. Microstructural and tribological properties of A356 Al-Si alloy reinforced with $\mathrm{Al}_{2} \mathrm{O}_{3}$ particles. Tribol Lett 2008; 32: 159-170.

25. Vencl A, Bobić I, Bobić B, et al. Erosive wear properties of ZA-27 alloy-based nanocomposites: Influence of type, amount and size of nanoparticle reinforcements. Friction 2019; 7: 340-350.

26. Bobić B, Vencl A, Ružić J, et al. Microstructural and basic mechanical characteristics of ZA27 alloy-based nanocomposites synthesized by mechanical milling and compocasting. I Compos Mater 2019; 53: 2033-2046.

27. Vencl A, Bobić I and Kandeva M. Influence of small addition of nano particles on mechanical and erosive wear properties of zinc-based nanocomposites. In: International Conference on "Trends in Nanotribology 2017" (TiN17), Trieste, Italy, 26-30 June 2017, posters.

28. Vencl A, Kandeva M and Bobić I. Influence of nanoparticles amount on erosive wear properties of ZA-27 alloybased dual-size composites. In: $1^{\text {st }}$ International Conference on Technological Innovations in Metals Engineering (TIME), Haifa, Israel, 30-31 May 2018, p.48.

29. Murphy S and Savaskan T. Metallography of zinc- $25 \%$ Al based alloys in the as-cast and aged conditions. Pract Metall 1987; 24: 204-221.

30. Flemings MC. Behavior of metal alloys in the semisolid state. Metall Trans A 1991; 22: 957-981.

31. Vencl A, Mrdak M and Hvizdos P. Tribological properties of WC-Co/NiCrBSi and Mo/NiCrBSi plasma spray coatings under boundary lubrication conditions. Tribol Ind 2017; 39: 183-191.

32. Vencl A, Vučetić $F$, Bobić B, et al. Tribological characterization in dry sliding conditions of compocasted hybrid A356/SiC ${ }_{p} / G_{p}$ composites with graphite macroparticles. Int J Adv Manuf Technol 2019; 100: 2135-2146.

33. Rohatgi PK, Liu Y and Ray S. Friction and wear of metal-matrix composites. In: Blau PJ (ed) ASM Handbook, Volume 18: Friction, Lubrication, and Wear Technology. Metals Park: ASM International, 1992, pp.801-811.

34. Zum Gahr K-H. Microstructure and wear of materials. Amsterdam: Elsevier, 1987.

35. Liu X. A study on the erosion and erosion-oxidation of metal matrix composites. PhD thesis, Helsinki University of Technology, Finland, 2003.

36. Peat T, Galloway A, Toumpis A, et al. The erosion performance of particle reinforced metal matrix composite coatings produced by co-deposition cold gas dynamic spraying. App/ Surf Sci 2017; 396: 1623-1634. 
37. Vencl A. Tribology of the Al-Si alloy based MMCs and their application in automotive industry. In: Magagnin L (ed) Engineered Metal Matrix Composites: Forming Methods, Material Properties and Industrial Applications. New York: Nova Science Publishers, 2012, pp.127-166.

38. Vučetić F, Veličković S, Milivojević A, et al. A review on tribological properties of microcomposites with ZA-27 alloy matrix. In: $15^{\text {th }}$ International Conference on Tribology - SERBIATRIB '17, Kragujevac, Serbia, 17-19 May 2017, pp.169-176.

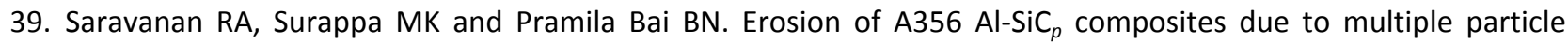
impact. Wear 1997; 202: 154-164.

40. Miyazaki N and Funakura S. Solid particle erosion behavior of metal matrix composites. J Compos Mater 1996; 30: 1670-1682.

41. Ninham AJ and Levy AV. The erosion of carbide-metal composites. Wear 1988; 121: 347-361.

42. Wilson $S$ and Ball A. Wear resistance of an aluminium matrix composite. In: First South African Colloquium: The Engineering Development and Application of Composite Materials, Johannesburg, South Africa, 23 July 1990, paper no. 5.

43. Laguna-Camacho JR, Vite-Torres $M$, Gallardo-Hernández EA, et al. Solid particle erosion on different metallic materials. In: Pihtili H (ed) Tribology in Engineering. Rijeka: InTech, 2013, pp.63-78. 

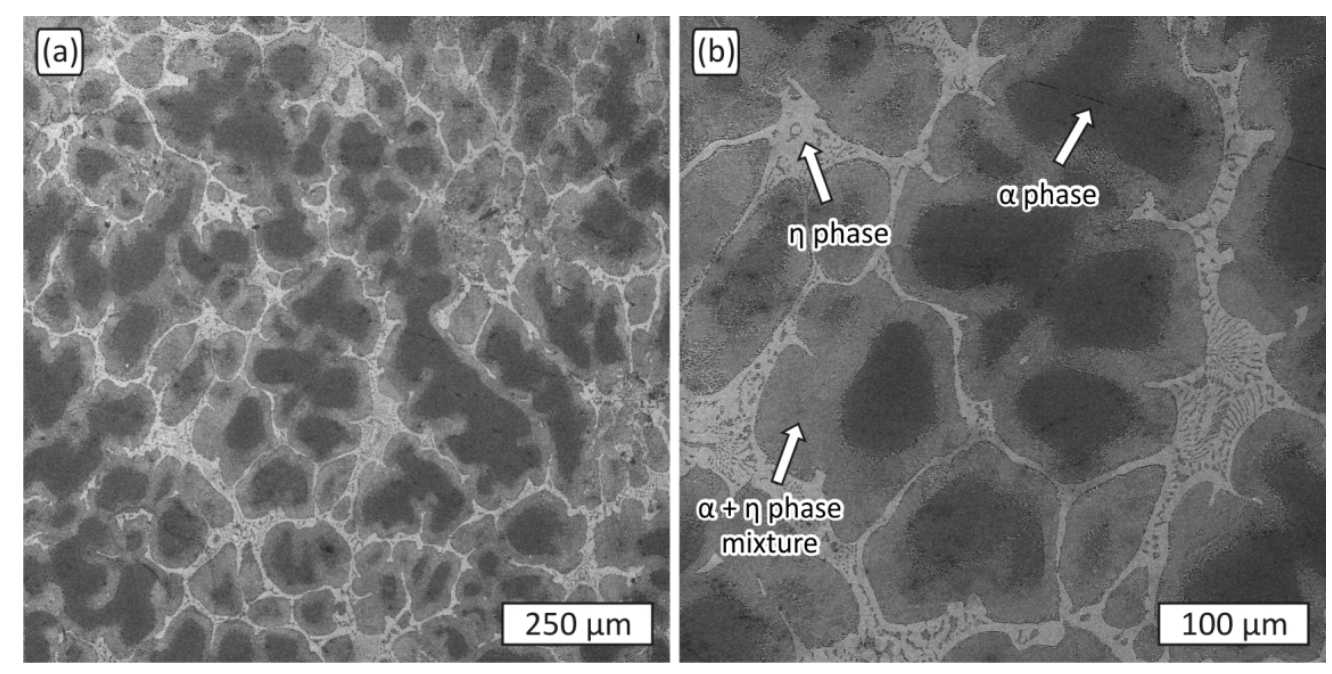

Microstructure of thixocasted ZA-27 alloy, SEM: (a) general view and (b) a phase formed by deagglomeration of large a phase region

$603 \times 299 \mathrm{~mm}(72 \times 72 \mathrm{DPI})$ 

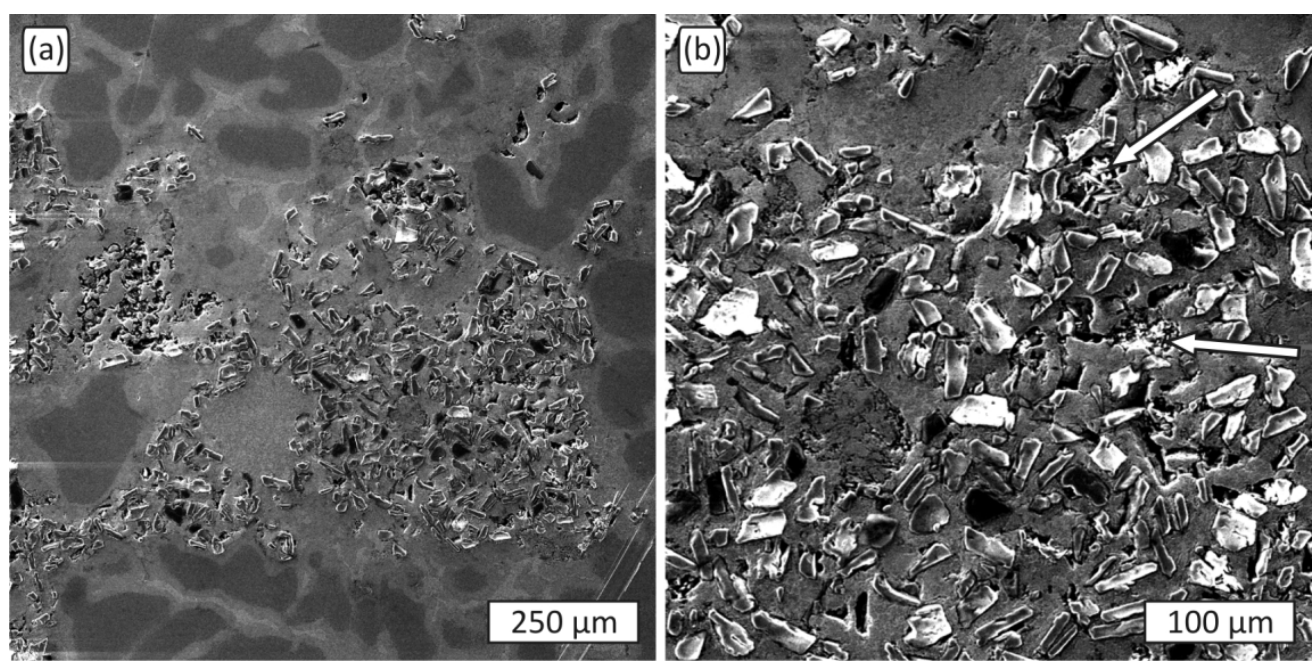

Microstructure of micro-nanocomposite MN-0.3, SEM: (a) general view, (b) microparticles distribution $603 \times 299 \mathrm{~mm}(72 \times 72 \mathrm{DPI})$ 

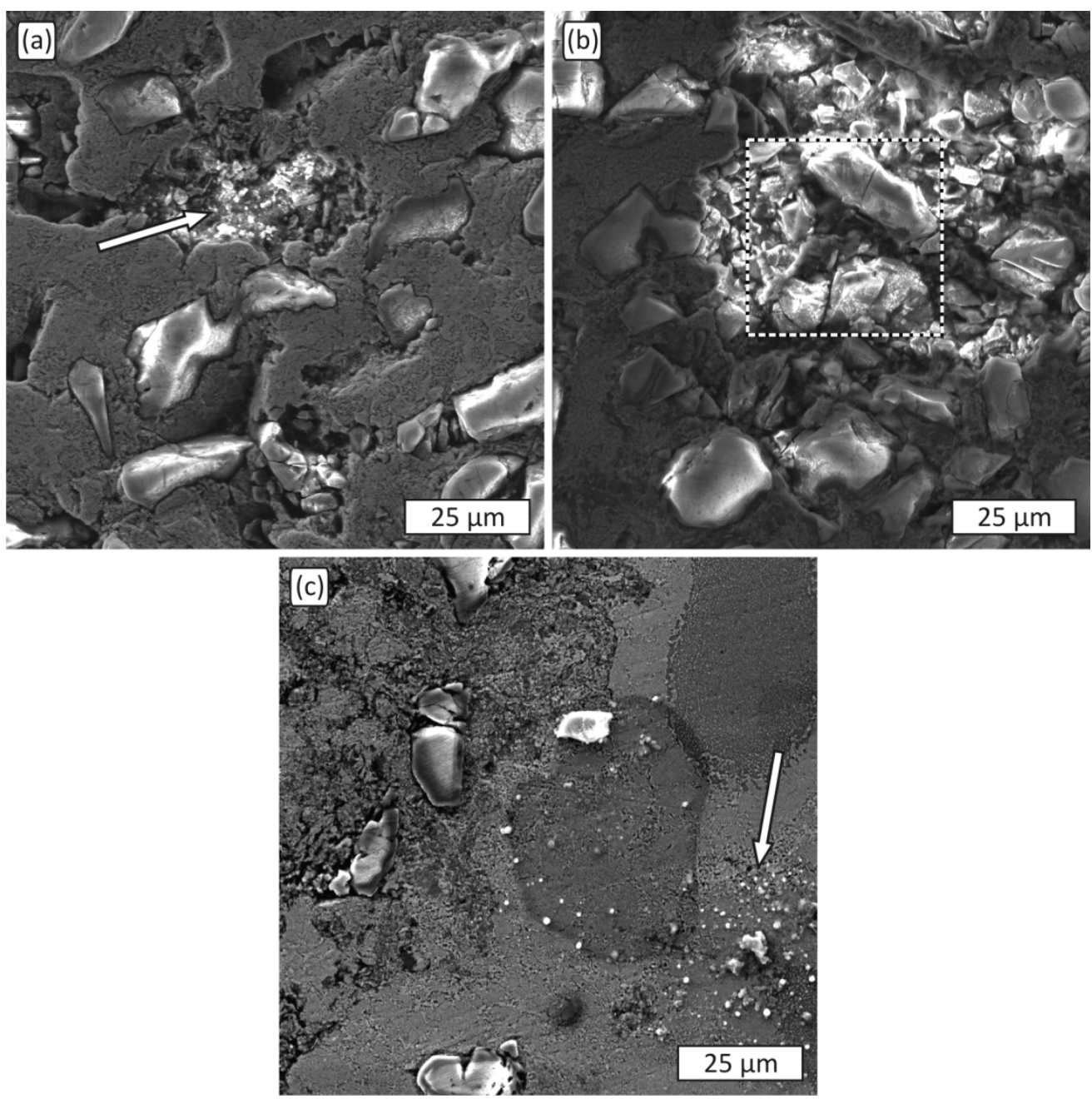

Microstructure of micro-nanocomposites (nanoparticle clusters distribution), SEM: (a) micro-nanocomposite $\mathrm{MN}-0.3$, (b) micro-nanocomposite MN-0.5 and (c) micro-nanocomposite MN-1.0

$603 \times 603 \mathrm{~mm}(72 \times 72 \mathrm{DPI})$ 


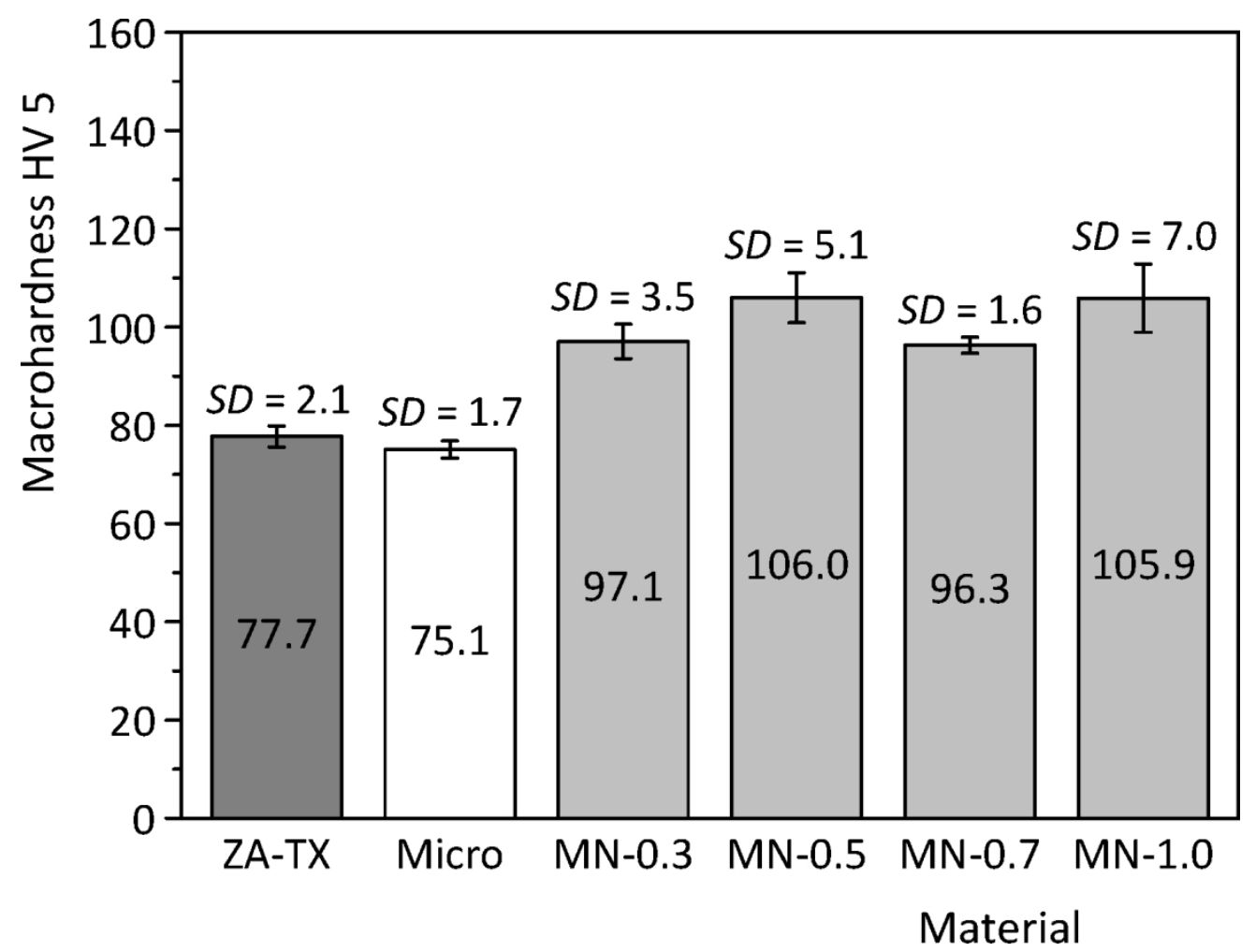

Macrohardness values and corresponding standard deviations (SD) of tested materials $590 \times 447 \mathrm{~mm}(72 \times 72 \mathrm{DPI})$ 


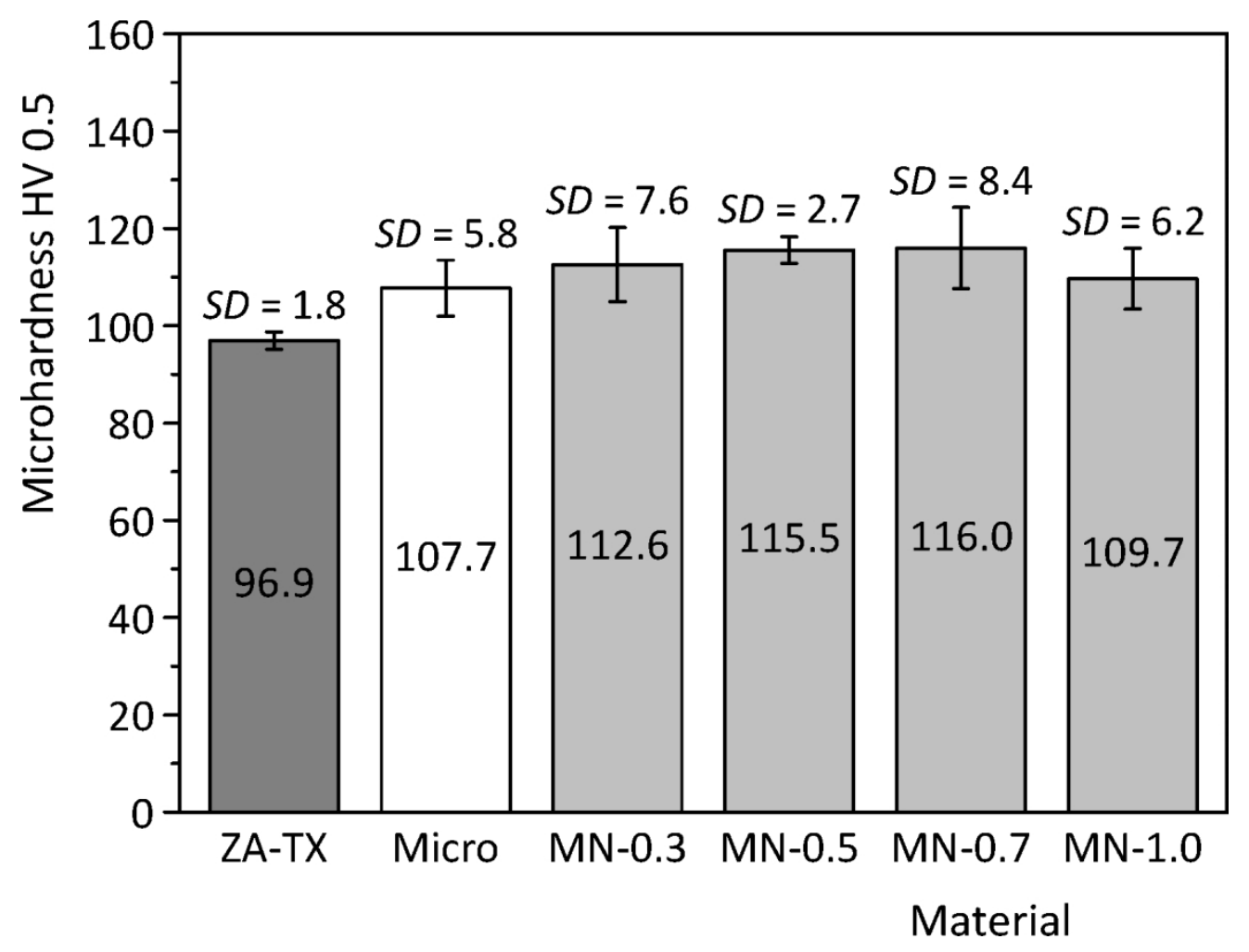

Microhardness values and corresponding standard deviations (SD) of tested materials $590 \times 447 \mathrm{~mm}(72 \times 72$ DPI $)$ 


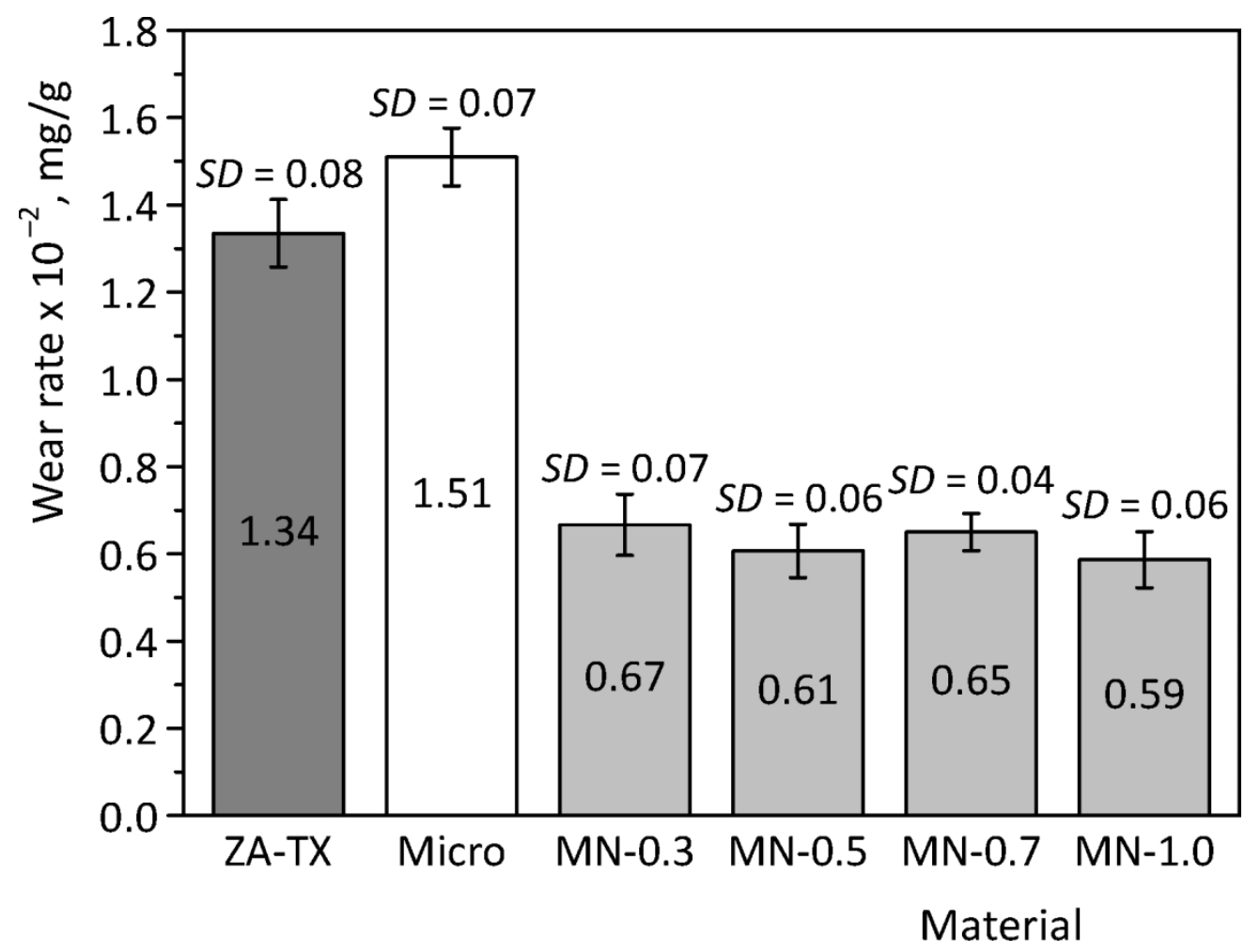

Erosive wear rate values and corresponding standard deviations (SD) of tested materials $590 \times 445 \mathrm{~mm}(72 \times 72 \mathrm{DPI})$ 

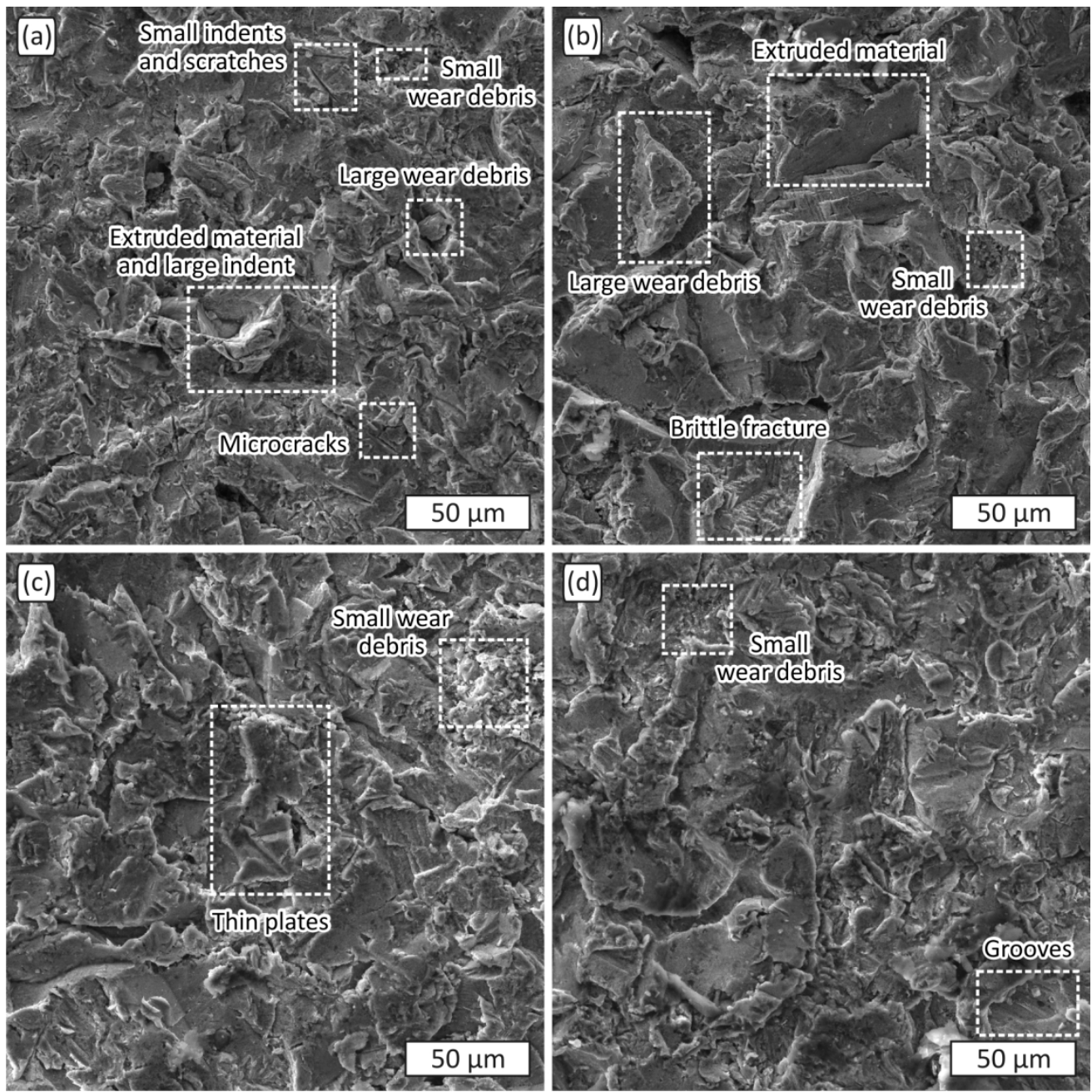

Worn surfaces of tested materials, SEM: (a) thixocasted ZA-27 alloy, (b) microcomposite, (c) micronanocomposite $\mathrm{MN}-0.3$ and (d) micro-nanocomposite $\mathrm{MN}-1$; all images are taken with the same magnification $(1000 \times)$

$603 \times 603 \mathrm{~mm}(72 \times 72 \mathrm{DPI})$ 